\title{
¿ES NECESARIO EL AMPARO ELECTORAL PARA PROTEGER DERECHOS POLÍTICOS EN PROCESOS ELECTORALES?
}

\author{
WALTER A. DÍAZZEGARRA*
}

\begin{abstract}
Resumen
La justicia constitucional peruana ha establecido que las resoluciones del Jurado Nacional de Elecciones pueden ser revisadas cuando afectan derechos fundamentales; siendo que el mecanismo adecuado es el proceso de Amparo; sin embargo, su uso no ha significado eficacia, toda vez, que son pocos los casos en que ha reparado el derecho conculcado y la mayoría de las veces termina solo determinando responsabilidad de las autoridades que vulneran estos derechos, de ahí la necesidad de evaluar la posibilidad de establecer un Amparo Electoral con trámite e instancias diferentes al Amparo clásico.
\end{abstract}

Palabras clave: Justicia electoral, derechos fundamentales, amparo.

\begin{abstract}
The Peruvian constitutional justice has established that the resolutions of the JNE can be revised when they affect fundamental rights; It is that the appropriate mechanism is the process of Amparo; however, its use has not meant effective, given that there are few cases that has repaired the violated right and most of the time ends only determining responsibility of the authorities that violate these rights, hence the need to assess the this possibility establish an Electoral Amparo - process and different instances with classic Amparo.
\end{abstract}

Keywords: Electoral justice, fundamental rights, amparo.

\section{Sumario}

1.- Introducción. 2.- Elecciones, derechos políticos y justicia electoral. 2.1.- Elecciones; 2.2.Derechos políticos. 2.3.- Justicia electoral. 3. Revisión de las resoluciones del Jurado Nacional de Elecciones: un tema zanjado. 3.1.- Normatividad de no revisión. 3.2.- Jurisprudencia internacional. 3.3.- Jurisprudencia nacional. 4. ¿Es materia electoral solo la afectación de derechos políticos en elecciones? 4.1 Materia electoral; 4.2 Derechos políticos de afiliados a Partidos Políticos: democracia interna. 4.3.- Materia electoral y derechos políticos. 5.- Procesos de amparo contra decisiones del JNE 2008 - 2015. 6.- Tesis de amparo electoral. 6.1.- Tesis permisiva. 6.2.Tesis Negativa. 7.- Agenda Pendiente: Proyectos propuestos. 8.- El JNE y la implementación de mecanismos de protección de derechos. 9.- Conclusión de las razones para un amparo electoral.

* Juez superior de la Corte Superior de Justicia de Lima Norte y docente universitario. El presente trabajo ha sido realizado tomando datos de la tesis doctoral "La Protección de los Derechos Políticos en los Procesos Electorales a través del Proceso Constitucional de Amparo". 


\section{Introducción}

Corresponde al sistema electoral dar legitimidad a las elecciones, no obstante ello, se han dado casos en los cuáles los derechos políticos de los postulantes a cargos de elección popular han sido vulnerados, y la realidad nos muestra que solo un (01) caso ha sido posible la reparación de derecho conculcado, ordenándose se le entregue la credencial como autoridad regional electa (EXP. N. ${ }^{\circ}$ 05448-2011-PA/TC, 13/6/ 2012).

Nuestra Constitución Política establece en sus Artículos 142 y 181 que las resoluciones del Jurado Nacional de Elecciones (JNE) en materia electoral son irrevisables, ha sido la jurisprudencia del Tribunal Constitucional vía proceso de Amparo que ha resuelto que procede la revisión si las resoluciones del Jurado Nacional de Elecciones vulneran derechos políticos en los procesos electorales, si bien pocos casos han sido estimados, el problema radica en el tiempo que demora la tramitación de los procesos de Amparo lo que no ha permitido obtener un pronunciamiento de fondo, toda vez que, el proceso eleccionario ya concluyó y era imposible reparar el derecho político vulnerado al ya ser elegidas nuevas autoridades, por lo que, solo ha correspondido determinar la responsabilidad del agresor o archivar el proceso de Amparo por sustracción de la materia.

Ahora se han diseñado proyectos que consagran el Amparo Electoral, con trámite diferenciado al Amparo clásico, para proteger los derechos políticos vulnerados y se tiene como fundamento que el cronograma electoral tiene etapas preclusivas y plazos perentorios. Lo que se advierte de la investigación realizada es que son pocos los casos de demandas de Amparo planteadas por afectación de derechos políticos en procesos electorales, correspondiendo a la gran mayoría a casos de autoridades municipales y/o regionales ya elegidas y que son cesadas por causales de vacancia y/o suspensión.

Además tenemos pronunciamientos de Tribunales Internacionales que nos han dicho que el Estado peruano debe implementar mecanismos de protección contra las resoluciones de los órganos electorales que afecten derechos políticos. Ahora corresponde evaluar si se hace necesario que se implemente el Amparo Electoral con procedimiento más rápido y diferenciado que el Amparo clásico.

Últimamente acabamos de ir a las urnas para elegir Presidente de la República, Congresistas y representantes ante el Parlamento Andino; proceso electoral donde se han producido desencuentros desde el Congreso (al dar una Ley que modificada algunas normas electorales, esto ya después de convocado el proceso de elecciones); las resoluciones del JEE y el Jurado Nacional de Elecciones; y el actuar de los candidatos excluidos al sugerir que se trata de elecciones no transparentes. No deja de llamar la atención que ya días después de la elección del 10 de abril del 2016 aún se estén publicando resoluciones que resuelven casos de exclusión de candidatos presidenciales y congresales, cuándo ya se produjo el acto de votación. 


\section{Elecciones, derechos políticos y justicia electoral}

\section{$2.1 \quad$ Elecciones}

David Butler' señala que: "Las elecciones son un procedimiento con normas reconocidas donde toda la población, o parte de esta, elige a una o varias personas para ocupar un cargo". Ahora las elecciones como la técnica de designación de representantes varia en su concepto según el sistema político que se adopte: Cuando el elector tiene la libertad de elegir amparado por ley son elecciones competitivas (sistema democrático); cuando tiene libertades limitadas hablamos de elecciones semicompetitivas (sistema autoritario); y en caso de no haber libertad estamos ante elecciones no competitivas (sistema totalitario).

El politólogo Dieter Nohlen ${ }^{2}$ señala que el rol de las elecciones (competitivas) en los sistemas democráticos es fundamental: En primer lugar, constituyen la base del concepto "democracia", los detentadores del poder son elegidos popularmente; en segundo lugar, son la fuente de legitimación tanto del sistema político, como de sus líderes; y, en tercer lugar, son el medio a través del cual se verifica la participación política en las grandes mayorías.

Es acertado el enfoque de José Antonio Crespo 3 que refiere: "el ejercicio de la democracia no se reduce a las prácticas electorales. No obstante, la democracia moderna es inconcebible sin una íntima asociación con las elecciones, a tal grado que el indicador fundamental de las sociedades democráticas es la realización de elecciones libres".

El sistema democrático es más adecuado a la realidad de hoy, en una especie de pacto social de todas personas que viven organizadamente, pues permite la participación de toda persona y a la vez les da legitimidad de reconocimiento tanto a los dirigentes como a sus instituciones.

\subsection{Derechos políticos}

Hay una relación directa entre el ejercicio de los derechos políticos y democracia como forma de organización del Estado, lo que supone el respeto de los derechos fundamentales dentro de un Estado Constitucional de Derecho.

Para Sonia Picado" "Los derechos políticos son aquel grupo de atributos de la persona que hacen efectiva su participación como ciudadano de un determinado

1 BUTLER, David (1991). Elecciones, en Vernon Bogdanor (ed.), Enciclopedia de las instituciones políticas, Madrid: Alianza Editorial, pp. 253 - 258.

2 NOHLEN, D. (1981). Sistemas electorales del mundo, Centro de Estudios Constitucionales, Madrid, pp. 82 115.

3 CRESPO, José Antonio (1995). Elecciones y Democracia. Instituto Federal Electoral. México: Cuadernos de Divulgación de Cultura Democrática.

4 PICADO, Sonia (2007). Derechos políticos como derechos humanos. Idea Internacional, Suecia. p. 48. 
Estado". Coincidentemente el jurista mexicano Javier Patiño Camarena ${ }^{5}$ refiere: Los ciudadanos participan en la vida política a través de los derechos políticos, que el derecho al voto, a ocupar cargos públicos de elección popular, a reunirse y asociarse para tratar asuntos políticos, y el derecho de petición en materia política. El maestro Luis Sánchez Agesta ${ }^{6}$ comenta que: "La expresión derechos políticos corresponde a una terminología científica, que no encuentra, normalmente correspondencia en los textos escritos".

Los derechos políticos son el conjunto de facultades que permiten a la persona (nacional o extranjera) participar en la vida política de una nación, teniendo un contenido constitucional y siendo la configuración legal que establecerá las condiciones para su participación.

La doctrina señala que los derechos políticos están comprendidos por el derecho al voto, derecho a ser elegido, derecho a dirigir a ejercer función pública, derecho de petición, derecho de reunión y derecho de asociación, entre otros.

\section{$2.3 \quad$ Justicia electoral}

El maestro mexicano Héctor Fix Zamudio7 señala que "Tradicionalmente la solución de los conflictos electorales se encomendaba a organismos de naturaleza política, pero en los últimos años se ha iniciado la tendencia de atribuir el conocimiento y decisión de estas controversias de claro contenido político pero con regulación jurídica, a órganos autónomos de carácter administrativo, a tribunales ordinarios o a órganos jurisdiccionales especializados, con predominio de estos últimos en los años más recientes".

La judicialización de los actos electorales pasa no solo por que existan órganos electorales autónomos y especializados, sino también un marco jurídico adecuado, una sinergia entre ambos, que nos permita brindar garantías necesarias para salvaguardar la protección de derechos políticos y la organización estadual; privarnos de esta garantía significa falta de legitimidad y por ende un caos de gobernabilidad y de las instituciones del Estado.

En el Perú se tiene que desde inicios de la república con el Reglamento Provisional del 2 de diciembre 1821 se reconoce el voto para los hombres libres y con renta, así como la conformación de Juntas electorales que reunidos en parroquia con los feligreses después de celebrar la misa elegían a delegados para que posteriormente reunidos con otros elijan a los representantes que iban a integrar la municipalidades. Si bien la

5 PATIÑOCAMARENA, Javier (1994). Derecho electoral mexicano. Instituto de Investigaciones Jurídicas UNAM, México DF, p. 61.

6 SÁNCHEZ AGESTA, Luis (1989). Derechos y deberes políticos. Diccionario Electoral. Centro Interamericano de Asesoría y Promoción Electoral, Costa Rica, p. 228.

7 FIXZAMUDIO, Héctor (2001). La justicia constitucional y la judicialización de la política. Ponencia en el seminario internacional Constitución y Democracia en los umbrales del siglo XXI. Lima: Universidad de Lima. 
Constitución de 1826 reconocía el Poder Electoral, es recién con el Decreto Ley $\mathrm{N}^{\circ}$ 7177 del 26 de mayo de 1931 que se crea el Jurado Nacional de Elecciones, como órgano autónomo.

El concepto "Justicia Electoral"8 que actualmente tiene una connotación amplia, porque incluye al: 1) derecho procesal electoral, orgánico y dinámico, relativo a todos los juicios y recursos jurisdiccionales electorales; 2) derecho procedimental electoral, es decir, el que tiene por objeto a los recursos electorales de naturaleza administrativa, contra las autoridades y los partidos políticos; 3) derecho procesal constitucional, en cuanto a la mecanismos procesales, para impugnar normas, consideradas contrarias a la Constitución; 4) derecho penal electoral, correspondiente a la tipificación de determinadas conductas como delitos electorales, federales y del fuero común; 5) derecho procesal penal electoral, que tiene por objeto al proceso, juicio o causa, con motivo de la comisión de delitos electorales; 6) derecho administrativo sancionador electoral, que tiene por objeto las conductas electorales ilícitas, tipificadas y sancionadas como infracciones administrativas electorales, así como las reglas jurídicas sobre la denuncia o queja y el procedimiento para tramitar y dictar resolución; finalmente, se puede incluir al 7) derecho procesal laboral electoral, que comprende los juicios y recursos, administrativos y jurisdiccionales, a favor de los servidores públicos de órganos electorales. Es necesario hacer la correspondiente conceptuación, clasificación y sistematización, en beneficio de la ciencia jurídica y del Estado de derecho democrático.

\section{Revisión de las resoluciones del Jurado Nacional de Elecciones: un tema zanjado}

\subsection{Normatividad de no revisión}

Históricamente las resoluciones del JNE no eran susceptibles de revisión en la vía judicial; así tenemos que por Decreto Ley $14250^{9}$ del año 1962, no era posible su revisión; la Constitución Política de 1979 no establece en forma expresa la no revisión, la Ley N² 2406910 del 11 de enero de 1985 reitero la irrevisabilidad; y, la Constitución de 199311, Ley Orgánica de Elecciones N 26859, art. 34 y la Ley Orgánica del JNE Nº

8 Diccionario de Derecho Procesal Constitucional y Convencional (2014). Poder Judicial de la Federación Consejo de la Judicatura Federal. Universidad Nacional Autónoma de México - Instituto de Investigaciones Jurídicas.

9 Decreto Ley 14250 de fecha 5 de diciembre de 1962.

Artículo $13^{\circ}$.- El Jurado Nacional de elecciones es la autoridad suprema en materia electoral, y contra sus decisiones no procede recurso algun (...).

10 Ley 24069.

Artículo 2.- “No procede ninguna acción judicial respecto de las resoluciones del Jurado Nacional de Elecciones.

11 Constitución Política de 1993.

Artículo $142^{\circ}$.- No son revisables en sede judicial las resoluciones del Jurado Nacional de Elecciones en materia electoral (...). 
26486, art. 21 vuelve a reiterar la irrevisabilidad. Irrevisibilidad que Eduardo García de Enterria ${ }^{12}$ llama "inmunidad de la jurisdicción".

\subsection{Jurisprudencia internacional}

El constitucionalista español Javier Díaz Revorio ${ }^{13}$ señala que "como principio, nada puede quedar al margen del control constitucional de un Estado de derecho, los límites de lo político, de lo administrativo y público están en el ámbito de lo jurídico y del derecho, sobre todo en materia de derechos fundamentales, así como en el adecuado y normal funcionamiento del sistema jurídico democrático. Desde este punto de vista el Tribunal Constitucional siempre debe tener la posibilidad de revisar en juicio de constitucionalidad, como línea de principio y como grado de excepción".

\section{a. Corte Interamericana de Derechos Humanos}

\section{Caso: Yatama vs Nicaragua ${ }^{14}$}

El presente caso se deriva de la adopción de Ley Electoral No. 331 en enero de 2000. Esta nueva ley no contempló la figura de las asociaciones de suscripción popular para que participaran en las elecciones. Solo se permitía la participación en los procesos electorales a través de la figura jurídica de partidos políticos. El 8 de marzo de 2000 miembros de la organización indígena Yapti Tasba Masraka Nanih Asla Takanka (YATAMA) intentaron obtener la autorización para ser reconocidos como partido político regional. No obstante, a pesar de los diversos recursos presentados, la solicitud fue denegada.

La Corte consideró que la prohibición de recursos ordinarios o extraordinarios contra las resoluciones del Consejo Supremo Electoral en materia electoral no implica que no existan controles judiciales. La independencia de un órgano estatal no es incompatible con la existencia de mecanismos de protección de los derechos fundamentales.

Artículo $181^{\circ}$.- Resoluciones del Pleno del Jurado Nacional de Elecciones

El Pleno del Jurado Nacional de Elecciones aprecia los hechos con criterio de conciencia. Resuelve con arreglo a ley y a los principios generales de derecho. En materias electorales, de referéndum o de otro tipo de consultas populares, sus resoluciones son dictadas en instancia final, definitiva, y no son revisables. Contra ellas no procede recurso alguno

14 Caso: Yatama vs. Nicaragua. En www.corteidh.or.cr/docs/casos/articulos/seriec_127_esp.pdf, consultada: 20 de mayo del 2015. 


\section{Caso Castañeda Gutman vs. Estados Unidos Mexicanos ${ }^{15}$}

El 5 de marzo de 2004, el señor Jorge Castañeda presentó al Consejo General del IFE una solicitud de inscripción como candidato independiente al cargo de Presidente para las elecciones del 2 de julio de 2006.

La Dirección Ejecutiva de Prerrogativas y Partidos Políticos, Dirección de Partidos Políticos y Financiamiento del Instituto Federal Electoral, informó al señor Castañeda Gutman que no era posible atender su petición en los términos afirmó que el derecho a ser postulado y ser votado para ocupar un cargo de elección popular a nivel federal, solo puede ejercerse a través de alguno de los partidos políticos nacionales que cuenten con registro ante el Instituto Federal Electoral. La Corte concluyó que el recurso de amparo no resulta procedente en materia electoral, la naturaleza extraordinaria de la acción de inconstitucionalidad y la inaccesibilidad e inefectividad del juicio de protección para impugnar la falta de conformidad de una ley con la Constitución; en la época de los hechos del presente caso no había en México recurso efectivo alguno que posibilitara a las personas cuestionar la regulación legal del derecho político a ser elegido previsto en la Constitución Política y en la Convención Americana. En razón de ello, la Corte concluye que el Estado no ofreció a la presunta víctima un recurso idóneo para reclamar la alegada violación de su derecho político a ser elegido.

\section{b. Comisión Interamericana de Derechos Humanos}

\section{Caso Susana Higushi vs. Estado peruano ${ }^{16}$}

Denuncia contra el Estado peruano, ya que el Pleno del JNE impidió su inscripción como candidata a la Presidencia de la República por la Agrupación Independiente "Armonía Frempol", para las elecciones generales, la Comisión Interamericana de Derechos Humanos llegó a un acuerdo amistoso; no obstante en su informe sostuvo:

“56.- Independientemente de la modalidad de administración electoral que decida adoptar un Estado, debe garantizar que las decisiones que aquella adopte y que puedan violar los derechos políticos consagrados en la Convención, sean objeto de un recurso efectivo ante jueces o tribunales (artículo 25 de la Convención), o al menos, de un recurso efectivo ante la propia autoridad electoral".

\subsection{Jurisprudencia nacional}

El TC peruano ha establecido jurisprudencialmente que no hay zona exenta de control constitucional cuando se vulneran los derechos fundamentales; $y$, finalmente ha revisado algunas de las resoluciones del JNE:

\footnotetext{
15 Caso Castañeda Gutman vs. Estados Unidos Mexicanos. En www.corteidh.or.cr/docs/casos/articulos/seriec_184_esp.pdf, consultada: 18 dejulio del 2014.

16 Informe N ${ }^{\circ} 119 / 99$ del 06 de octubre de 1999. Caso 11.428. Susana Higushi Miyagawa vs. Estado Peruano.
} 
a) Casos de autoridades municipales o regionales ya elegidas:

STC No 5854-2005-PA/TC 8/11/ 2005 (caso Pedro Andrés Lizana Puelles Infundado).

STC N 5396-2005-PA/TC: 6/9/2005, (caso Ramírez García - RegionalInfundado).

STC N 2730-2006-PA/TC 21/7/2006 (caso Arturo Castillo Chirinos Municipal-Fundada).

b) Casos de candidatos en procesos electorales:

STC No 2366-2003-AA/TC.6/4/2004, (Caso Espino Espino -candidato municipal- Improcedente-denuncia penal), inicio de amparo electoral.

STC N. ${ }^{\circ}$ 05448-2011-PA/TC, 13/6/ 2012 (Percy Rogelio Zevallos FretelElecciones Regional - Fundado).

A ello se agrega que el Colegio de Abogados del Callao que demandó inconstitucionalidad de la Ley 26842 que establecía que las resoluciones del JNE en materia electoral no son revisables en sede judicial, por sentencia STC N 00007-2007-PI/TC de fecha 19 de junio de 2007, el TC declaró fundada la demanda, precisando que ninguna demanda de Amparo podrá paralizar el calendario electoral.

\section{4. ¿Es materia electoral solo la afectación de derechos políticos en elecciones?}

\subsection{Materia electoral}

Cabe precisar que el JNE, debido a su peculiar naturaleza de ser un organismo jurisdiccional y administrativo, simultáneamente, no solo emite resoluciones jurisdiccionales en materia electoral, sino también resoluciones administrativas, referidas a asuntos que no constituyen materia electoral. De allí que no resulte vana la precisión realizada por las normas citadas al establecer como irrevisables, únicamente, sus resoluciones en materia electoral.

Carlo Magno Salcedo Cuadros (2006)17 señala que:

"Dentro del proceso electoral ocurren una serie de actos administrativos, todos los cuales tienen por objeto permitir que los ciudadanos ejerzan el derecho de sufragio y que los votos de estos permitan la elección de las autoridades o determinen el resultado sobre una decisión sometida a consulta ciudadana, traduciendo la voluntad ciudadana de manera exacta y oportuna. Entre estos actos destacan la elaboración del padrón electoral, la determinación de las circunscripciones administrativas, la conformación de las mesas de sufragio, la inscripción de las fórmulas o listas de candidatos, el diseño del material electoral (cédulas de

17 SALCEDO CUADROS, Carlo Magno (2006). La inconstitucionalidad de las normas sobre vacancia de autoridades regionales y municipales. Apuntes a propósito de la vacancia del alcalde Castillo Chirinos. Actualidad Jurídica. № 15 , oct. 2006, pp. 277 y ss. 
sufragio, actas electorales, carteles de candidatos, listas de electores, etcétera), la votación propiamente dicha, el escrutinio y el cómputo de los resultados (...). La vacancia de las autoridades regionales o municipales no se encuentra regulada en ley electoral alguna (como la Ley Orgánica de Elecciones, la Ley de Elecciones Regionales o la Ley de Elecciones Municipales), sino en la Ley Orgánica de Gobiernos Regionales (LOGR) y en la Ley Orgánica de Municipalidades (LOM), respectivamente. Y no está regulada en ley electoral alguna porque no es un tema electoral, por ningún lado por donde se lo mire".

La Dra. Elva Greta Minaya Calle (2012) ${ }^{18}$ refiere:

"El Código Electoral debe definir qué se entiende por materia electoral, la cual comprende el conjunto de actos, actuaciones, trámites y resoluciones propiamente referidos al proceso electoral o que se originen en él, realizados por organismos electorales, organizaciones politicas, los candidatos, los electores, los medios de comunicación, las empresas publicitarias y encuestadoras".

El Jurado Nacional de Elecciones en su proyecto de Código Electoral señala:

“Articulo I.- Alcances

El presente Código regula los mecanismos, a través de los cuales, los ciudadanos ejercen su derecho a la participación política en los procesos y procedimientos que este determina, así como el funcionamiento de los distintos organismos y órganos electorales.

Articulo VI.- Tipos de proceso electoral

El presente Código y el Código Procesal Electoral regulan los siguientes procesos electorales

1) Elección de autoridades (...)

2) Procesos de ejercicio de los derechos de participación y control ciudadano

(...)

Los procedimientos vinculados a la vacancia y suspensión de autoridades municipales y regionales tienen naturaleza especial distinta a los procesos electorales antes señalados".

Queda claro que la materia electoral tiene relación directamente con el sufragio que se realiza dentro de un proceso electoral, ya sea directa o indirectamente. Situaciones como la vacancia o suspensión de autoridades ediles o regionales no son temas de sufragio, ya que obedecen a incumplimientos legales para seguir el cargo para el que fueron elegidos, pero totalmente ajenos al acto de sufragio que los llevó a ostentar el cargo.

18 MiNAYA CALLE, Elva Greta. La jurisdicción electoral. Mi opinión singular y en discordia. Editorial Adrus, Lima, 2012, p. 11. 


\subsection{Derechos políticos de afiliados a Partidos Políticos: democracia interna}

Los partidos o agrupaciones políticas canalizan el derecho del ciudadano de participación política; problema complejo es desarrollarse en democracia sin partidos $\mathrm{u}$ organizaciones políticas, consideramos que es el medio idóneo para que el ciudadano ejerza sus derechos políticos.

Para Flavia Freidenberg refiere que la democracia interna de los partidos políticos debe comprender 3 dimensiones ${ }^{19}$. Las dimensiones a tener en cuenta eran tres: a) selección de candidatos a cargos de elección popular y de autoridades partidistas; b) participación de minorías y sectores sociales subrepresentados (mujeres, jóvenes, grupos étnicos) en el proceso de toma de decisiones y en la definición programática del partido, y c) rendición de cuentas de los candidatos, cargos públicos y autoridades del partido a la militancia.

\section{La Constitución de 1993 establece:}

Artículo $35^{\circ}$

Los ciudadanos pueden ejercer sus derechos individualmente o a través de organizaciones políticas como partidos, movimientos o alianzas, conforme a ley. Tales organizaciones concurren a la formación y manifestación de la voluntad popular. $\mathrm{Su}$ inscripción en el registro correspondiente les concede personalidad jurídica. La ley establece normas orientadas a asegurar el funcionamiento democrático de los partidos políticos, y la transparencia en cuanto al origen de sus recursos económicos y el acceso gratuito a los medios de comunicación social de propiedad del Estado en forma proporcional al último resultado electoral general.

\section{Ley de Partidos Políticos $\mathrm{N}^{\circ} 28094$ y modificatorias}

Artículo $19^{\circ}$.-Democracia interna

La elección de autoridades y candidatos de los partidos políticos y movimientos de alcance regional o departamental debe regirse por las normas de democracia interna establecidas en la presente Ley, el estatuto y el reglamento electoral de la agrupación política, el cual no puede ser modificado una vez que el proceso ha sido convocado.

Artículo $20^{\circ}$.-Del órgano electoral

La elección de autoridades y de los candidatos a cargos públicos de elección popular se realiza por un órgano electoral central conformado por un mínimo de tres (3) miembros. Dicho órgano electoral tiene autonomía respecto de los demás órganos

19 FreidenberG, Flavia. Democracia interna en los partidos políticos, en Nohlen, Dieter, "Tratado de derecho electoral comparado de América Latina", 2a. ed., México y San José, Fondo de Cultura Económica, Instituto Interamericano de Derechos Humanos, IFE e IDEA International, cap. XXV, pp. 627-678. 
internos y cuenta con órganos descentralizados también colegiados, que funcionan en los comités partidarios.

Toda agrupación política debe garantizar la pluralidad de instancias y el respeto al debido proceso electoral. El órgano electoral central tiene a su cargo la realización de todas las etapas de los procesos electorales del partido, incluidas la convocatoria, la inscripción de los candidatos, el cómputo de votos o la verificación del quórum estatutario, la proclamación de los resultados y la resolución de las impugnaciones a que hubiere lugar. Para tal efecto, debe establecer las normas internas que correspondan, con arreglo al reglamento electoral de la agrupación política.

El Dr. Virgilio Hurtado $\mathrm{Cruz}^{20}$ señala: “Existe en la LPP un vacío normativo por omisión legislativa, en la medida que este corpus iuris no desarrolla acciones concretas para que el JNE cumpla con el mandato que le confiere el inciso 3) del artículo $178^{\circ}$ de la $\mathrm{CP}$ en el proceso de democracia interna que es donde se inicia el ejercicio del derecho a ser elegido".

Consideramos que si ahora no se encuentra regulado un proceso de Amparo contra afectación de derechos políticos al interior de los Partidos Políticos, ello no debería implicar que vía jurisprudencias se habilite, ya que se trata de derechos fundamentales que tienen que repararse oportunamente.

Los caminos pueden ser los siguientes:

- El JNE conozca en grado de apelación contra la afectaciones de derechos políticos de los afiliados a las organizaciones políticas, para ello tendría que acudirse a una modificación legal de la Ley de Partidos Políticos.

- Proceda Amparo Electoral por afectación de derechos políticos de los partidarios por parte de la agrupación política que forman parte, con trámite diferenciado al Amparo ordinario.

\subsection{Materia electoral y derechos políticos}

Materia electoral comprende todos los actos referidos al proceso eleccionario, que se inician con la convocatoria a elecciones hasta la proclamación y entrega de credenciales a los electos, sean actos o decisiones administrativos y jurisdiccionales. Ahora ello no impide que por configuración legal se amplié las facultades para resolver conflictos de las autoridades ya elegidas para acreditar al reemplazante, nos estamos refiriendo a casos de suspensión y/o vacancia de autoridades ediles y regionales ya elegidas, o en caso de vacancia de Congresistas para acreditar al reemplazante.

20 HURTADO CRUZ, Virgilio. El derecho a ser elegido candidato en elecciones internas: un derecho que debe tutelarse en la jurisdicción electoral, en http://aceproject.org/regions-en/countries-and-territories/PE/case-studies/elderecho-a-ser-elegido-candidato-en-elecciones, consultada: 13 de mayo del 2015. 
Ahora apreciamos que todos los mecanismos implementados o proyectos se dirigen a proteger derechos políticos de candidatos de agrupaciones políticas, más no los derechos de los candidatos dentro del partido o agrupación política, situación que debe apreciarse, cuando se observe los procesos de Amparo que se han presentado.

\section{Procesos de amparo contra decisiones del JNE 2008 - 2015}

Veamos algunos datos estadísticos sobre los procesos de Amparo interpuestos contra resoluciones del JNE, que fueron en el orden de 186 expedientes, discriminados en las siguientes materias: afectaciones durante procesos electorales, vulneraciones post electorales y temas administrativos como entidad empleadora.

a. 186 Procesos de Amparo presentados contra el JNE.

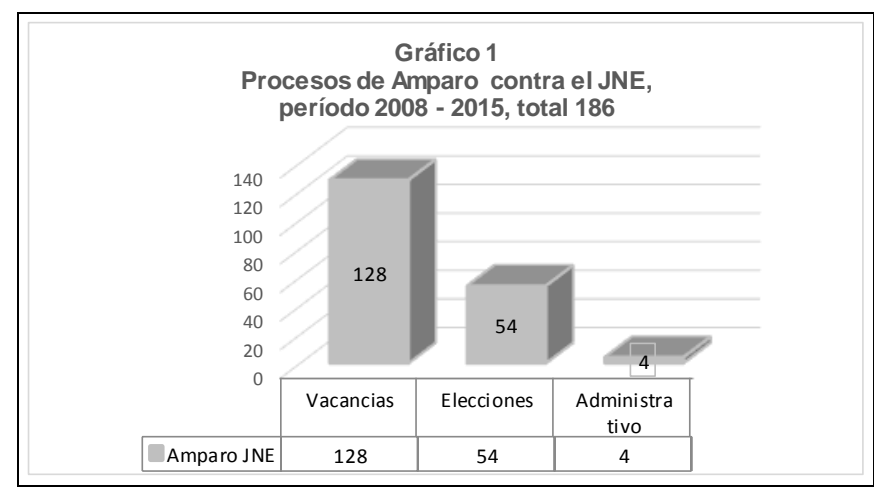

Fuente: Procuraduría Pública delJNE.

b. Proceso electoral: 54 demandas contra resoluciones del JNE en elecciones

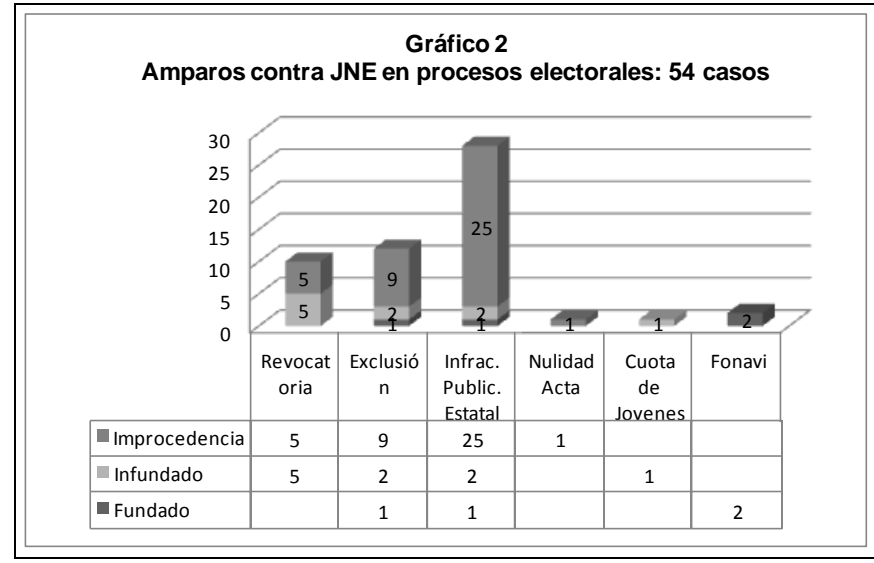

Fuente: Procuraduría Pública delJNE. 
c. Procesos de Amparo en procesos electorales: Derecho afectado

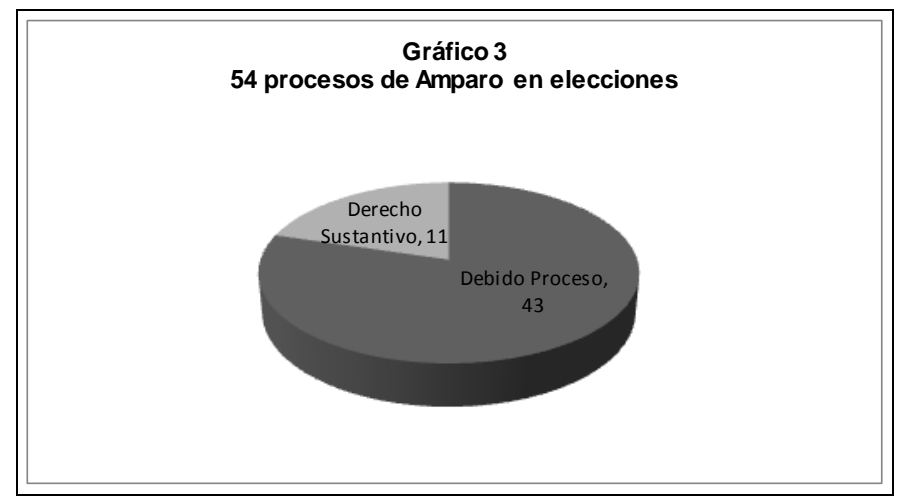

Fuente: Procuraduría del JNE y elaboración de la investigación.

d. Plazo de duración de los Procesos de Amparo contra el JNE: 186 demandas

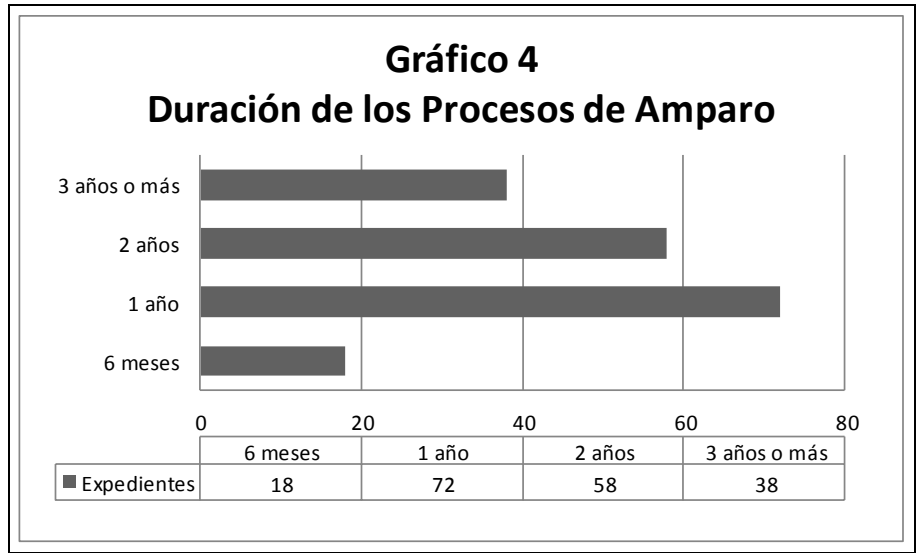

Fuente: Procuraduría del JNE y elaboración de la investigación.

\section{Tesis de amparo electoral}

En las tesis de implementación del Amparo Electoral es necesario evaluar 2 conceptos indesligable: Juridicidad el ordenamiento jurídico electoral, así como las actuaciones de órganos electorales y terceros; y, la gobernabilidad de la administración pública (ejecutiva, regional o municipal). 


\subsection{Tesis permisiva}

Permite la revisión de las resoluciones de los órganos o tribunales electorales, países como: Argentina las decisiones de la Cámara Nacional Electoral son revisables vía recurso extraordinario ante la Corte Suprema de Justicia; España permite el amparo electoral contra las limitaciones a candidaturas como proclamación de autoridades ante el Tribunal Constitucional; Colombia ha establecido vía jurisprudencial por el Tribunal Constitucional que procede acción de tutela (Amparo) contra las resoluciones del Consejo Nacional Electoral; y, Costa Rica, entre otros.

La tesis permisiva permite la revisión de la resolución electoral ante Tribunales Judiciales que no forman parte de los órganos electorales, mediante los procesos de Amparo u otro análogo. No obstante, puede presentarse que dentro de los propios órganos electorales exista un mecanismo de protección frente a las vulneraciones de derechos políticos, una especie de Amparo Electoral.

\section{a. Amparo electoral ante Tribunal Constitucional, instancia final}

A nivel del Perú los juristas nacionales Domingo García Belaúnde²1, Samuel Abad Yupanquii $^{22}$, Jhonny Tupayachi Sotomayor ${ }^{23}$, Christian Donayre Montesinos ${ }^{24}$, César Landa Arroyo ${ }^{25}$, Pedro A. Hernández Chávez ${ }^{26}$, Gerardo Eto Cruz²7, Javier Alva Orlandini, Eloy Espinoza - Saldaña Barrera ${ }^{28}$ y Omar Sar ${ }^{29}$, entre otros, coinciden que las resoluciones del JNE en materia electoral de tutela de los derechos políticos sean revisadas ante el Tribunal Constitucional, mediante el Amparo Electoral con un trámite diferente al Amparo clásico, donde el TC como instancia única o final ante Tribunal Constitucional, siendo la primera instancia la Sala Constitucional y Social de

21 GARCíA BelaúnDE, Domingo (2009). El Amparo electoral en su laberinto. Sus vicisitudes en el ordenamiento peruano. El Derecho Procesal Constitucional en Perspectiva. - Lima: Idemsa.

22 ABAD YUPANQUI, Samuel (2002). El proceso de amparo en materia electoral: Un instrumento para la tutela de los derechos fundamentales. Revista Elecciones de la ONPE, año 1, núm. 1, noviembre del 2002, pp. 189 y ss.

23 TUPAYACHISOTOMAYOR, Jhonny (2008). La Reforma del Sistema Electoral y la Procedencia del Amparo Electoral en el Perú: Análisis y Critica. Revista de la Gaceta Constitucional No 8, agosto 2008, pp. 113 y ss.

24 DONAYRE MONTESINOS, Christian (2010). En Defensa del Amparo Electoral. Editorial Palestra, Lima, pp. 99 y SS.

25 LANDA ARroYo, César (2011). Organización y funcionamiento del Tribunal Constitucional. Palestra Editores, Lima.

26 HERNÁNDEZ CHÁVEZ, Pedro A. (2012). El amparo electoral y la reposición de una autoridad elegida excluida por el Jurado Nacional de Elecciones. Gaceta Constitucional N 57, Lima setiembre 2012, p. 34.

27 ETO CRUZ, Gerardo (2014). El proceso constitucional de amparo en la Constitución de 1993 y su desarrollo. Pensamiento Constitucional, Volumen $18, \mathrm{~N}^{\circ} 18$, pp.145-174.

28 ESPINOSA-SALDAÑA BARRERA, Eloy (2005). Apuntes sobre la revisabilidad de las decisiones del Jurado Nacional de Elecciones Peruano en materia electoral. En: Revista Jurídica del Perú, Año LV Nº 65. Lima, NoviembreDiciembre 2005, pp. 14-15.

29 SAR, Omar (2010). Amparo Electoral, Derechos Fundamentales y Conflicto institucional. Para optar el grado de doctor en Derecho en la Pontificia Universidad Católica Perú, en http://www.researchgate.net/publication/259472140_Amparo_electoral_Derechos_Fundamentales_y_c onflicto_institucional, consultada: el 26 de febrero del 2015. 
la Corte Suprema, aunque como es propio con diversos matices, algunos solo revisión del debido proceso, otros sobre aspectos materiales y formales.

\section{b. Amparo electoral ante el JNE}

Los destacados juristas Henry Pease ${ }^{30}$ y Julio Ortecho Villena ${ }^{31}$ consideran que se puede flexibilizar una formula del Amparo Electoral que dentro del JNE se constituyan instancias para tratar sobre la denuncia de afectación de derechos políticos en el desarrollo de los procesos electorales. Asimismo, el profesor Carlo Magno Salcedo Cuadros ${ }^{32}$ considera que el control puede estar dentro del propio Tribunal Electoral o el Poder Judicial.

\subsection{Tesis negativa}

Niega la posibilidad de cualquier recurso o mecanismo de cuestionamiento de las decisiones electorales. El país que tiene este modelo es México la Ley de Amparo en su Artículo 73 apartado "VII. El juicio de amparo es improcedente: contra las resoluciones o declaraciones de los organismos y autoridades en materia electoral".

Los juristas nacionales Juan Falconí Gálvez ${ }^{33}$, Enrique Bernales y Alberto Otárola ${ }^{34}$, Marcial Rubio Correa ${ }^{35}$, Enrique Javier Mendoza Ramírez ${ }^{36}$, Félix Enrique Ramirez Sánchez ${ }^{37}$, entre otros.

\section{Agenda pendiente: Proyectos propuestos}

Tenemos un tema zanjado sobre la revisión de las resoluciones del JNE cuando vulnerar derechos fundamentales, y ya a nivel supranacional se nos ha recomendado implementar un recurso rápido y sencillo para proteger derechos políticos; tengamos en cuenta que dichas las decisiones supranacionales que nos vinculan son la del caso

30 PEASE, Henry (2005). Sesión de la Comisión de Constitución y Reglamento del 17 de octubre del 2005, primera legislatura ordinaria, en http://www2.congreso.gob.pe/Sicr/ApoyComisiones/comision2005.nsf/1ActasComisiones/A48EBE4 8345F6174052570AF00617EF2/\$FILE/ACTACONST17-10-2005.pdf, consultada: 5 de mayo del 2015.

31 ORTECHO VILlENA, Julio (2008). Jurisdicción ordinaria y jurisdicciones especiales. En http://www.geocities.ws/tdpcunmsm/proconst1.html, consultada: 23 de marzo del 2015.

32 SALCEDO CUADROS, Carlo Magno (2008). La procedencia e improcedencia del amparo electoral en el ordenamiento jurídico peruano. Gaceta Constitucional N ${ }^{\circ} 12$, Diciembre 2008, pp. 77 - 93.

33 FALCONÍ GÁLVEZ, Juan (2006). Las contradicciones del "supremo intérprete constitucional", cuando conoce la materia electoral. Sobre la necesidad de precisar constitucionalmente el contenido conceptual del término "justicia electoral". Revista Ita Ius Esto. Revista de los Estudiantes de Derecho, 28 de noviembre del 2012.

34 BERNALES, Enrique y Alberto OTÁROLA (1999). La Constitución de 1993. Análisis Comparado. Lima: Constitución y Sociedad (ICS). p. 672.

35 RUBIO, Marcial (1999). Estudio de la Constitución de 1993. Tomo V. Lima: Fondo Editorial Pontificia Universidad Católica del Perú, pp. 167-170.

36 MENDOZA RAMÍREZ, Enrique Javier (2007). Sobre la autonomía del Jurado Nacional de Elecciones. Revista Oficial del Poder Judicial 1/1, p. 74 y ss.

37 RAMíREZ SÁNCHEZ, Félix Enrique (2006). La irrevisabilidad de los fallos del Jurado Nacional de Elecciones vs. Control Constitucional: Una polémica que no cesa. En Revista Jurídica del Perú Año LVI No 66, pp. 243-244. 
Yatama vs Nicaragua tramitado ante la CIDH y Susana Higuchi tramitado ante la $\mathrm{CIDH}$; ambas decisiones por candidaturas a elecciones populares.

Veamos a nivel de propuestas cómo se implementa este recurso sencillo y rápido, que dentro del derecho comparado se le llama "Amparo Electoral", cuáles son las propuestas a nivel del Congreso de la República, a su vez, las acciones que ha tomado el Estado peruano, a través del JNE.

a) Proyecto de Ley $\mathbf{N}^{\circ}$ 1579/2012-CR. Presentado por el congresista Marco Tulio Falconí Picardo presento el siguiente proyecto de ley que establece la modificatoria de la Ley $N^{\circ} 28237$ e incorpora los Artículos 4-A y 59-A al Código Procesal Constitucional, Ley que regula el Amparo Electoral Artículo el artículo 4-A a la Ley N²8237.

"Artículo 4-A Amparo Electoral

El amparo procede respecto de las resoluciones emitidas en última instancia por el Jurado Nacional de Elecciones que resuelvan tachas y vacancias, dictadas con directa y manifiesta afectación de derechos constitucionales.

Artículo 59-A.- Trámite del Amparo Electoral

El amparo contra resoluciones de última instancia emitidas por el Jurado Nacional de Elecciones en materia electoral, a que se refiere el artículo 4-A, se sujeta a las siguientes reglas:

La demanda debe presentarse dentro de los cinco días de notificada la resolución cuestionada ante la Sala Constitucional y Social de la Corte Suprema de la República (...).

Contra las resoluciones denegatorias de la pretensión cabe Recurso de Agravio Constitucional que se interpone en el plazo de tres días contados a partir del día siguiente de notificada la impugnada: Concedido el recurso la causa es elevada en el día al Tribunal Constitucional, que resuelve sin mayor trámite dentro de los tres días siguientes".

b) Proyecto de Ley $\mathbf{N}^{\circ}$ 13648-2005. Presentado por el congresista Yonhy Lescano A.

Artículo 1.- Modificase los artículos 51 y 107 del Código Procesal Constitucional, con el siguiente texto.

Artículo 51․ Jueces competentes y plazo de resolución

(...)

Si la afectación de derechos se origina en una resolución judicial, o en una resolución del Consejo Nacional de la Magistratura, o una resolución del Jurado Nacional de 
Elecciones, a demanda se interpondrá ante la Sala Constitucional de la Corte Suprema que dictará sentencia en el plazo que no exceda de 5 días.

Contra la resolución que declara infundada o improcedente la demanda, procede recurso de agravio constitucional ante el Tribunal Constitucional, dentro del plazo de 5 días contados desde el día siguiente de notificada la resolución. Concedido el recurso, el Presidente de la Sala remite el expediente, de inmediato, al Tribunal Constitucional; el cual se pronuncia dentro del plazo de 5 días. (...)

c) Proyecto en minoría del congresista Natale Amprimo Pla. Ley que modifica los Artículos $15^{\circ}, 18^{\circ}, 19^{\circ}, 20^{\circ} 44^{\circ}$ y $51^{\circ}$ de la Ley 28237, Código Procesal Constitucional.

Artículo $4^{\circ}$.- Incorpórese como último párrafo del artículo $18^{\circ}$ de la Ley 28237, Código Procesal Constitucional, el siguiente texto:

"Artículo 18.- Recurso de agravio constitucional.

(...)

Tratándose del proceso de amparo iniciado cuando la afectación de derechos se origina en una resolución del Consejo Nacional de la Magistratura o en una resolución del Jurado Nacional de Elecciones, contra la resolución de la Sala Constitucional y Social de la Corte Suprema de Justicia de la República que declara infundado o improcedente la demanda, procede recurso de agravio constitucional ante el Tribunal Constitucional, dentro del plazo de dos días hábiles contados desde el día siguiente de notificada la resolución. Concedido el recurso, el Presidente de la Sala remite al Tribunal Constitucional el expediente dentro del plazo máximo de un día hábil, bajo responsabilidad."

d) El Tribunal Constitucional y su propuesta de Amparo. EXP. N. ${ }^{\circ}$ 5854-2005PA/TC (Caso Pedro Andrés Lizana Puelles). En tal sentido, de conformidad con lo establecido en el artículo $107^{\circ}$ de la Constitución, este Tribunal propone al Congreso de República introducir en el CPC, en el más breve plazo posible, las modificaciones conducentes a:

- Reducir el plazo de prescripción para interponer una demanda de amparo contra una resolución del JNE en materia electoral.

- Las demandas de amparo contra una decisión del JNE en materia electoral sean presentadas ante la Sala Constitucional y Social de la Corte Suprema; y en segunda instancia ante el Tribunal Constitucional, mediante la interposición de un recurso de agravio constitucional.

- Que jueces constitucionales presten preferencia a los procesos de Amparo en materia electoral.

- Los plazos deben ser perentorios. 


\section{El JNE y la implementación de mecanismos de protección de derechos}

\subsection{Recurso extraordinario por afectación al debido proceso del JNE}

Resolución $\mathrm{N}^{\mathrm{o}}$ 044-2002-JNE se aprueba el Texto Único de Procedimientos Administrativos que en el ítem $\mathrm{N}^{\mathrm{0}} 40$, establece el denominado "pedido atípico de nulidad" de resoluciones expedidas por el Pleno del JNE u otro recurso con distinta denominación con la finalidad que el JNE revise sus resoluciones, estableciendo la tasa equivalente al 10\% de la UIT más el costo de la publicidad de la resolución.

Resolución N 306-2005-JNE, su fecha 22 de octubre del 2005, se establece en materia electoral el "recurso extraordinario por afectación al debido proceso y a la tutela procesal efectiva" (...)

\section{SE RESUELVE:}

Artículo Único.- Establecer en materia electoral el "Recurso Extraordinario por afectación al debido proceso y a la tutela procesal efectiva" el cual deberá ser presentado debidamente fundamentado dentro del tercer día de notificado con la resolución del Pleno del Jurado Nacional de Elecciones, y será resuelto en el plazo de 3 días.

\subsection{Resolución N. ${ }^{\circ}$ 0333-2015-JNE - Definición de Jurados Electorales Especiales, sedes y competencia material para el proceso de Elecciones Generales y de Representantes Peruanos ante el Parlamento Andino 2016.}

Artículo Segundo: ESTABLECER la competencia material de los Jurados Electorales Especiales correspondientes al proceso de Elecciones Generales y de Representantes Peruanos ante el Parlamento Andino 2016, y la respectiva fecha de instalación, conforme al siguiente detalle:

1. El Jurado Electoral Especial de Lima Centro 1 se instalará el 1 de diciembre de 2015, y tendrá competencia para recibir, calificar, resolver tachas, conocer expedientes de exclusión e inscribir las solicitudes de inscripción de fórmulas de candidatos a la Presidencia y Vicepresidencias de la República, las solicitudes de inscripción de listas de candidatos a representantes peruanos ante el Parlamento Andino y las solicitudes de inscripción de listas de candidatos a congresistas de la República del distrito electoral de Lima y residentes en el extranjero. Asimismo, resolverá, en primera instancia, los pedidos de nulidad total de elecciones que se formulen respecto de las elecciones antes referidas.

3. Los Jurados Electorales Especiales de Chachapoyas, Huaraz, Abancay, Arequipa 1, Huamanga, Cajamarca, Callao, Cusco, Huancavelica, Huánuco, Ica, Huancayo, Trujillo, Chiclayo, Huaura, Maynas, Tambopata, Mariscal Nieto, Pasco, Piura 1, Puno, Moyobamba, Tacna, Tumbes y Coronel Portillo se instalarán el 15 de enero de 2016 y tendrán competencia para recibir, calificar, resolver tachas, conocer expedientes de 
exclusión e inscribir las solicitudes de inscripción de listas de candidatos a congresistas de la República del distrito electoral respectivo. Asimismo, resolverán, en primera instancia, los pedidos de nulidad total de elecciones congresales de sus respectivas circunscripciones.

\subsection{Proyecto de Código Electoral presentado por el JNE al Congreso de la República el 2 de diciembre del 2011}

Artículo 12.- Jurados Electorales Descentralizados

12.1 Los Jurados Electorales Descentralizados son órganos que tienen competencia jurisdiccional dentro de la circunscripción electoral correspondiente.

12.2 Se encuentran conformados por tres (3) miembros:

a. Un Presidente, que es designado por la Corte Superior de la circunscripción donde se encuentra la ciudad que es sede del JED, entre los jueces superiores titulares en actividad;

b. Un miembro designado por el Ministerio Público entre los Fiscales Superiores titulares en actividad de la circunscripción donde se encuentra la ciudad que es sede del JED;

c. Un miembro designado por Concurso Público por el JNE, quien debe cumplir los requisitos que se exigen para la postulación a juez superior del Poder Judicial, conforme al reglamento que apruebe el Pleno del JNE, pudiendo ser designados trabajadores o funcionarios al servicio del Estado, siempre que soliciten previamente la licencia correspondiente.

12.3 Los miembros a que se refiere el numeral anterior serán designados por un período de dos (02) años, pudiendo ser ratificados por la correspondiente institución que los designó solo por un período adicional de dos (02) años. Para efectos de la ratificación, el JNE emitirá un informe respecto de la actuación de los miembros en el ejercicio de sus funciones, el cual será remitido a la institución que los designó.

12.4 En el instrumento de designación de los miembros de los Jurados Electorales Descentralizados, deberá señalarse el accesitario del miembro designado. Ante la ausencia del Miembro Titular, temporal o permanente, corresponde asumir funciones al miembro accesitario; en caso que este último no asuma funciones, la institución que designó a los miembros, deberá designar a un nuevo titular y su correspondiente accesitario.

12.5 Sus funciones, atribuciones, régimen laboral y remunerativo, así como otras regulaciones respecto del ejercicio de sus funciones son los establecidos 
en el presente Código, el Código Procesal Electoral y la Ley Orgánica del JNE.

12.6 Los Jurados Electorales Descentralizados se rigen, en lo aplicable, por las normas del Pleno del JNE, respecto de sus obligaciones, impedimentos, quórum, sesiones, acuerdos, fallos, deliberaciones, nulidades y votaciones.

12.7 Existen Jurados Electorales Descentralizados permanentes, constituidos de acuerdo a la densidad de electores, así como la cercanía y facilidad de acceso de las poblaciones. El JNE deberá definir las circunscripciones sobre las cuales se constituirán Jurados Electorales Descentralizados permanentes.

12.8 Una vez convocados los procesos electorales, el JNE podrá redefinir las circunscripciones, sedes y ámbitos de competencia y convocar a Jurados Electorales Descentralizados temporales. Para tal efecto, deberá notificar a las instituciones encargadas de la designación de sus miembros a fin que designen a sus representantes, dentro de un plazo no mayor de diez (10) días de efectuada la respectiva convocatoria. Asimismo, las circunscripciones electorales, sus respectivas sedes y ámbitos de competencia podrán ser modificados por razones técnicas, a solicitud de la ONPE.

Artículo 13.- Pluralidad de instancias de la jurisdicción electoral

13.1 Los Jurados Electorales Descentralizados, permanentes o temporales, constituirán la primera instancia de la jurisdicción electoral, que incluye los procesos de elección de autoridades y de ejercicio de los derechos de participación y control ciudadano, cuestionamientos de decisiones administrativas vinculadas a la materia electoral.

13.2 Los procedimientos sobre cuestionamientos contra decisiones del ROP y las resoluciones de la ONPE y el RENIEC que agotan la vía administrativa, son conocidos, en primera instancia jurisdiccional, por el Jurado Electoral Descentralizados de Lima. En caso que exista más de un JED en Lima, corresponde al JNE señalar cuál es el que conocerá estos cuestionamientos, en el instrumento que constituye los Jurados Electorales Descentralizados.

13.3 Los procedimientos sobre vacancia y suspensión de autoridades regionales y municipales son conocidos, en primera instancia jurisdiccional, por los Jurados Electorales Descentralizados permanentes.

13.4 Los procedimientos tramitados ante los Jurados Electorales Descentralizados temporales que no cuenten con pronunciamiento de primera instancia jurisdiccional hasta el cierre del proceso electoral serán 
asumidos por el JED permanente que asume competencias en dicha circunscripción.

13.5 La segunda y definitiva instancia de la jurisdicción electoral, así como en materia de vacancia y suspensión de autoridades regionales y municipales, es el Pleno del JNE.

\section{Conclusiones de las razones para un amparo electoral}

a) El Perú es un Estado Social y Democrático de Derechos cuya Constitución protege y respeta los derechos fundamentales; que considera sus normas de aplicación inmediata. El Tribunal Constitucional ha interpretado que no hay zonas exentas de control constitucional, de ahí que las resoluciones del JNE cuando vulneran derechos fundamentales es posible de ser revisadas mediante el proceso de Amparo.

b) El JNE desde diciembre del año 2011 presento 2 proyectos: Código Electoral y Código Procesal Electoral. Es necesario integrar en un solo cuerpo jurídico la dispersa normatividad jurídica para que haya coherencia. El proyecto de Código Electoral establece en sus Arts. 12 y 13 la posibilidad de tener Jurado Electorales Permanentes Descentralizados que funcionarían como 1ra. Instancia, y el JNE sería la 2da. Instancia, ello es acertado por 2 razones: i) Está creando una justicia electoral especializada (actualmente los JEE son temporales y funcionan solo unos meses previos a la fecha de elecciones); $y$, ii) Crea instancias jurisdiccionales. Dichos proyectos están configurando que se entiende por materia electoral y atribuyen otras competencias al JNE, más allá del proceso electoral concluido.

c) El JNE ha hecho esfuerzos denodados para garantizar el respeto de derechos fundamentales y la transparencia del proceso eleccionario, recientemente en la Elecciones Generales del 2016 tuvo que establecer que para ver los temas de inscripción y demás actos se constituyera el JEE Lima Centro 1, quién ha conocido el tema de listas presidenciales y congresales para Lima; y para luego constituirse el JNE en segunda instancia.

d) En los últimos comicios electorales no se ha interpuesto proceso de Amparo alguno; no obstante, hay un caso de un candidato cuya agrupación política no logró su inscripción y que ha recurrido en forma directa a la Comisión Interamericana de Derechos Humanos, obviamente, en razón de la demora por podría tener de acudir al Amparo regulado en nuestras leyes.

e) Nuestra investigación realizada ha demostrado que de los 186 procesos de Amparo interpuestos durante los períodos 2008 - 2015, solo 54 fueron referidos a procesos electorales; 128 en materia vacancia de autoridades ya elegidas y 4 administrativos en reconocimiento de derechos de trabajadores 
del JNE solo un (01) caso fue declarado fundado y se ordenó entregar la credencial al candidato elegido; $y$, otro único caso de reponer a la autoridad edil vacada, lo que terminó con la quema de un local municipal, es decir no se pudo cumplir. En análisis no lleva a concluir que la principal causa fue la demora en la tramitación del Amparo, pues los términos electorales son perentorios y sus etapas preclusivas, contexto que impide resolver con prontitud la violación alegada y con ello la ineficacia en la protección de derechos políticos.

f) Es evidente que sí es necesario la implementación de un proceso de Amparo Electoral con un procedimiento más rápido que el Amparo clásico y con otras instancias, lo que permitirá una mayor garantía. Ahora este nuevo proceso Amparo Electoral tiene que ver con materia electoral, pero limitadamente en casos de vulneración de derechos políticos de candidatos, afectaciones de derechos de unión, información y conexos; además de reclamaciones de candidatos en elecciones internas de agrupaciones políticas; más no proceder en el tema de escrutinios; a ello ha de agregarse que el Amparo Electoral proteja derechos de autoridades políticas elegidas y que sean separadas de su cargo, como el caso de vacancia y/o suspensión. Es también ya un requerimiento supranacional para que implementemos un mecanismo de protección que sería el Amparo Electoral.

g) Es un notable avance que ya el JNE en las Elecciones Generales del 2016 haya procurado que hayan 2 instancias, tanto en lo que se refiere a fórmulas presidenciales, congresales y del Parlamento Andino; sin duda ha permitido un mejor análisis; sin embargo, no ha sido de mucha ayuda los plazos, ya que se aprecia que aún después de ya realizadas las elecciones el 10 de abril del 2016 continúan publicándose resoluciones de exclusión y otras en las que el JNE anula todo y dispone se emita una nueva resolución, lo cual no es adecuado; obviamente ello se debe a las normas que establecen los plazos.

h) Nos falta especialización de jueces en materia electoral, ello se logrará con JEEs permanente; actualmente la composición de los mismos es adecuada, como ello se dará desde el inicio una seguridad en las decisiones y resoluciones adoptadas. También urge la aprobación del proyecto de Código Electoral y el Código Procesal Electoral, instrumentos jurídicos que darán mayor organicidad a las elecciones, ello brindará seguridad jurídica y garantizará la gobernabilidad del país. La implementación de éstos aspectos conllevará a garantizar los derechos fundamentales en el desarrollo de procesos electorales, y quizá el poco uso del Amparo Electoral que podrá ser utilizado en otros campos aún no previstos como los derechos de los afiliados a una organización política, pero debemos cumplir con la agenda pendiente dispuesta por la jurisdicción supranacional. 